\title{
Restriction of Measles Virus Gene Expression in Measles Inclusion Body Encephalitis
}

\author{
Knut Baczko, Uwe G. Liebert, Roberto Cattaneo, \\ Martin A. Billeter, Raymond P. Roos, \\ and Volker ter Meulen
}

\author{
From the Institut für Virologie und Immunbiologie, \\ Universität Würzburg, Würzburg, Federal Republic of \\ Germany; the Institut für Molekularbiologie I, Universität \\ Zürich, Zürich, Switzerland; and the Department of \\ Neurology, University of Chicago, Chicago, Illinois
}

\begin{abstract}
Measles virus (MV) infection in brain tissue of a patient with measles inclusion body encephalitis was characterized by immunologic and biochemical techniques. Of the five major structural proteins of $\mathrm{MV}$, only nucleocapsid $(\mathrm{N})$ protein and phosphoprotein $(\mathrm{P}$ protein) were consistently detected in diseased brain areas. In contrast, hemagglutinin protein was seen only occasionally, and no membrane and fusion proteins were found in any of the sections studied. Messenger RNAs (mRNAs) specific for these five viral proteins were detected in all brain extracts examined; however, the mRNAs for the envelope proteins were clearly underrepresented in comparison with lytically infected cells. Only the mRNAs for $\mathrm{N}$ and $\mathrm{P}$ proteins appeared active in in vitro translations. These findings indicate quantitative differences in the pattern of mRNA expression in brain tissue and a restricted expression of $\mathrm{MV}$ envelope proteins in infected cells as observed in subacute sclerosing panencephalitis.
\end{abstract}

Measles inclusion body encephalitis (MIBE) is an opportunistic infection occurring as a severe complication of acute measles in immunodeficient individuals [1]. Frequently associated with malignancy of the lymphatic or reticuloendothelial system, this CNS disease has several similarities to subacute sclerosing panencephalitis (SSPE). Neuropathological lesions found in MIBE consist of Cowdry type A inclusion bodies in neurons and glial cells, nerve cell loss, gliosis, diffuse and nodular proliferation of microglia, and perivascular round cell infiltrations. By electron microscopy, nucleocapsid $(\mathrm{N})$ structures of paramyxoviruses can be seen located mainly in the cytoplasm of infected cells. No budding viruses or released particles of virus have been observed, and only occasionally has infectious virus been isolated [2]. However, several clinical and immunologic differences exist between MIBE and SSPE. The incubation period between acute mea-

Received for publication 30 November 1987.

This work was supported by funds from the Deutsche Forschungsgemeinschaft and the Schweizer Nationalfonds.

We thank Drs. E. Norrby and T. A. Sato for providing antibodies to measles virus, Jeanette Roller for technical assistance, Fritz Ochsenbein for preparing the photographs, and Helga Kriesinger for typing the manuscript.

Please address requests for reprints to Dr. Volker ter Meulen, Institut für Virologie und Immunobiologie, Universität Würzburg, Versbacher Strasse 7, 8700 Würzburg, Federal Republic of Germany. sles and the onset of MIBE is much shorter than that in SSPE. MIBE has a course of a few days to a few weeks, whereas SSPE usually lasts for many years. Subjects with MIBE demonstrate a reduced antibody response to measles virus (MV), in contrast to the hyperimmune reaction in SSPE.

In view of the immunodeficient state, it is surprising that this opportunistic infection of the CNS does not lead to acute encephalitis with the synthesis of infectious MV, as is seen in experimental infections $[3,4]$. Conceivably the replication of MV in brain tissue may be defective, as in SSPE. This interpretation is supported by the observation that in some cases of MIBE no antibodies to MV membrane (M) protein are found, whereas the humoral immune response to other viral structural proteins can be demonstrated.

In this study we characterized the virus-cell interaction in brain tissue from a patient with MIBE. RNA was isolated from the brain and analyzed by both northern blot hybridization with strand-specific riboprobes derived from parts of the six MV genes and by the ability of the messenger RNAs (mRNAs) to direct the synthesis of viral proteins in vitro. In addition, the presence of five major structural proteins of MV was assessed in infected brain tissue with a panel of monoclonal antibodies by using immunohistological techniques. The observed defects in replication of MV virus in MIBE were compared with those described in SSPE [5-8]. 


\section{Materials and Methods}

Patient. The clinical course and the pathological findings have been described in detail [9]. A 22-mo-old girl was diagnosed as having acute lymphoblastic leukemia by bone marrow aspiration. Treatment with various immunosuppressive drugs induced remission of the malignancy, but the further course was complicated by development of acute measles at the age of $41 \mathrm{mo}$. Two months later a CNS disease with seizures developed, which progressed to a comatose state and status epilepticus. The girl died four months later. Pathological examination of the brain revealed severe cortical necrosis with few surviving neurons and massive infiltration of macrophages. Eosinophilic inclusion bodies, which consisted of paramyxovirus $\mathbf{N}$ structures, were detectable. There was no evidence of budding virus. In numerous attempts, isolation of virus was unsuccessful. The patient's serum contained antibodies to MV hemagglutinin $(\mathrm{H})$, fusion $(\mathrm{F})$, and $\mathrm{N}$ proteins. In the CSF, only antibodies to $\mathrm{N}$ protein were found.

Tissue processing. Brain tissue from our patient was obtained shortly after death, immediately frozen, and stored $-70 \mathrm{C}$.

Immunofluorescence. For evaluation of in vivo synthesis of MV proteins and determination of the relative frequency of the $\mathrm{MV}$ proteins present in brain cells, a double-labeling indirect immunofluorescence technique was used [8]. Serial, $6-\mu \mathrm{m}$-thick, frozen sections were cut from several brain regions, fixed in acetone for $20 \mathrm{~min}$ at $-20 \mathrm{C}$, and then incubated with pooled monoclonal antibodies to different epitopes of MV structural proteins: phosphoprotein ( $P$ protein), $\mathrm{M}, \mathrm{F}, \mathrm{H}$, and biotinylated antibodies to $\mathrm{N}$. The sources of the antibodies were our laboratory $[10,11]$, Dr. E. Norrby (Karolinska Institute, Stockholm) $[12,13]$, and Dr. T. A. Sato (National Institute of Health, Tokyo) [14]. FITC-conjugated antibodies to mouse immunoglobulins and avidin-Texas red were subsequently applied. Sections were washed and mounted in glycerol. The number of cells exhibiting specific labeling with the different monoclonal antibodies and their relative frequency were determined by using a fluorescence microscope (Leitz, Wetzlar, FRG).

Extraction of RNA. RNA was extracted from frozen brain tissue [6]. Samples from different brain regions were disrupted mechanically and homogenized in guanidinium isothiocyanate buffer, and the RNA was pelleted by centrifugation through cesium chloride. The pellet was dissolved in guanidinium hydrochloride, reprecipitated in ethanol, and finally dissolved in $100 \mathrm{~m} M \mathrm{NaCl}, 1 \mathrm{~m} M$ EDTA, and $10 \mathrm{~m} M$ HEPES ( $\mathrm{pH}$ 7.0). The mRNAs were selected by oligo-dthymidine chromatography.

Northern blots. MV-specific RNAs were analyzed as described previously $[6,15]$. Ten micrograms of total RNAs isolated from infected HeLa cells or MIBE brain tissue was loaded onto a broad slot of a $1.2 \%$ agarose-formaldehyde gel together with a mixture of standard RNAs synthesized in vitro containing segments of MV mRNA species [16]. After electrophoresis, the RNA was blotted onto nitrocellulose paper, which was cut into strips. Sets with one strip of each blot and one strip from a blot containing 4 fmol of each standard RNA exclusively (external standards) were then hybridized in the same bag with a ${ }^{32}$ P-labeled RNA probe of one of the MV genes [16]. After autoradiography of the strips, the bands corresponding to the MV mRNAs and to the internal and external standards were cut out, and the amount of radioactivity bound was determined.

In vitro translation and immunoprecipitation. The ability of the different MV mRNAs to direct the synthesis of the respective proteins was investigated using an in vitro translation system [6]. Products made in vitro were immunoprecipitated using a polyclonal rabbit antiserum to $\mathrm{MV}$ and monospecific antisera to $P, H, N$, and $M$ proteins. The total translate and the immunoprecipitated proteins were analyzed by $10 \%$ SDS-PAGE [5]. Attempts to identify $F$ protein were unsuccessful, because none of the available monospecific or monoclonal antibodies to $\mathrm{F}$ protein were able to detect it in in vitro translation reactions using mRNAs from Vero cells lytically infected with MV.

\section{Results}

Detection of $M V$ structural proteins in infected brain tissue by immunohistology. To assess the presence of MV structural proteins in infected brain cells, we incubated cryostat-cut brain sections with a panel of monoclonal antibodies to five structural proteins ( $N, P, M, F$, and $\mathrm{H}$ ) of $\mathrm{MV}$. The antibody used reacted with different epitopes of each structural protein. $\mathrm{N}$ and $\mathrm{P}$ proteins were easily visualized in brain cells, whereas $\mathrm{H}$ protein could only occasionally be seen (table 1 ). In contrast, $\mathrm{M}$ and $\mathrm{F}$ proteins could not be detected in any area or section 
Table 1. Detection of MV structural proteins in brain cells by double-labeling immunofluorescence.

\begin{tabular}{lc}
$\begin{array}{l}\text { Antibody to } \\
\text { protein }\end{array}$ & $\begin{array}{c}\text { No. (\%) of } \\
\text { cells positive }\end{array}$ \\
\hline $\mathrm{N}$ & $438(100)$ \\
$\mathrm{P}$ & $416(95)$ \\
$\mathrm{H}$ & $17(4)$ \\
$\mathrm{F}$ & 0 \\
$\mathrm{M}$ & 0 \\
\hline
\end{tabular}

NOTE. Monoclonal antibodies reacting with the respective proteins were pooled as described previously [8]. Positive cells were counted in 10 visual fields from three different brain regions-cerebral cortex, white matter, and cerebellum - using a $\times 40$ objective. The percentage of cells positive is given relative to reactivity for $\mathrm{N}$ protein.

tested, independent of the monoclonal antibody used.

The fluorescence patterns of the three detectable MV structural proteins differred. Monoclonal antibodies to MV N protein gave the most widespread fluorescent staining in the cytoplasm of the cellular processes of the cell bodies, as well as within inclusion bodies of oligodendrocytes, astrocytes, and neurons (figure 1, top). Monoclonal antibodies to $\mathrm{P}$ protein gave a strong fluorescent staining that was similar in appearance to the staining for $\mathrm{N}$ protein, except that no nuclear inclusion bodies were stained (data not shown). In contrast, monoclonal antibodies to $\mathrm{H}$ protein resulted in a weak, diffuse fluorescence of the cytoplasm (figure 1, bottom).

Analysis of MV mRNAs in brain tissue by northern blots. Total RNA derived from brain tissue of the patient with MIBE and MV-infected HeLa cells was analyzed for the presence of virus-specific RNAs by northern blots using riboprobes of negativestrand polarity derived from five MV genes [16]. Lytically infected HeLa cells contained all six MV mRNAs (figure 2A). Those for N, P, M, F, and $\mathrm{H}$ appear as strong bands. The bands of weaker intensity represent bicistronic and tricistronic transcripts of adjacent genes [6]. The two bands in figure 2A, lane $\mathrm{M}$ - one above the M mRNA and the other between the M-F and M-F-H polycistronic RNAs result from cross-hybridization of the GC-rich probe with $18 \mathrm{~S}$ and $28 \mathrm{~S}$ ribosomal RNA [16]. Owing to the longer exposure, the intensity of these bands is stronger in figure 2B. Total RNA isolated from brain tissue of the patient with MIBE reacted strongly with the $\mathrm{N}$ and $\mathrm{P}$ probes (figure $2 \mathrm{~B}$ ). However, the amounts of the $M, F$, and $H$ mRNAs are significantly
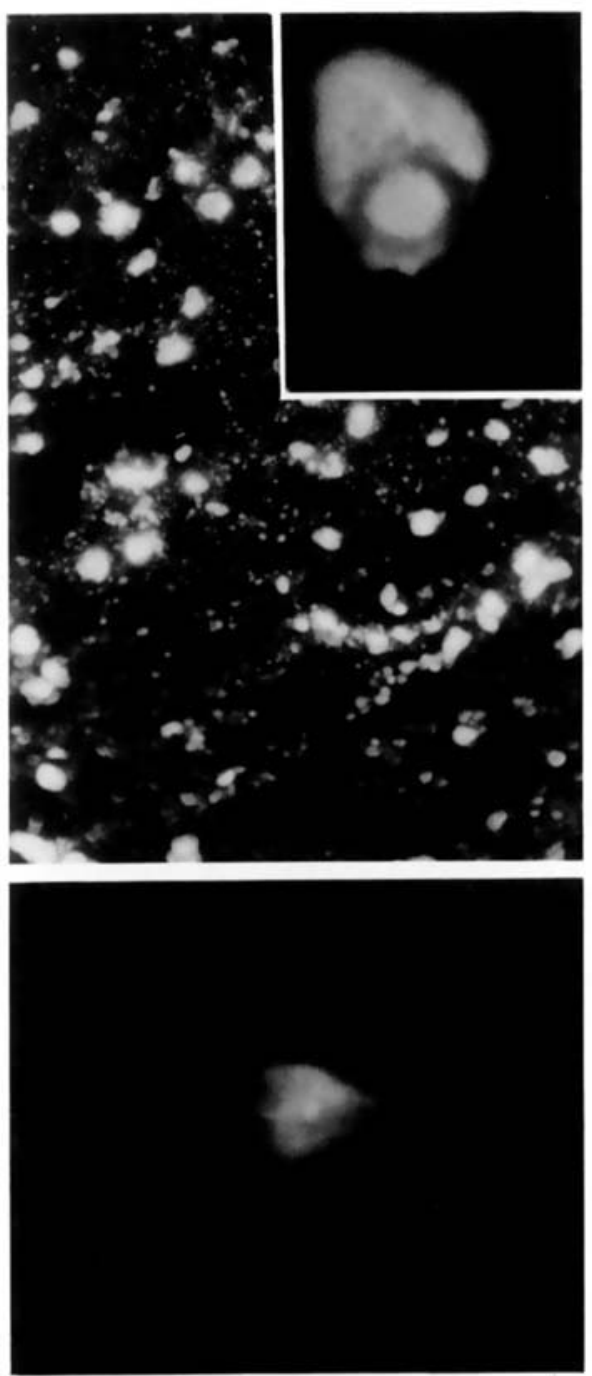

Figure 1. Indirect immunofluorescence using pooled monoclonal antibodies to $\mathrm{N}$ and $\mathrm{H}$ proteins of $\mathrm{MV}$. Top, numerous cells stain for $\mathrm{N}$ protein. Cell processes reveal granular staining ( $b a r=30 \mu \mathrm{m}$ ); and inclusion bodies ( $\mathrm{in}$ set) are also strongly positive $($ bar $=11 \mu \mathrm{m})$. Bottom, fluorescence for the $\mathrm{H}$ protein is weak and diffuse, restricted to single cells (bar $=20 \mu \mathrm{m}$ ).

reduced in comparison with lytically infected cells. In addition, a band of weak intensity migrating more slowly than the 16-kilobase genome, is detected in figure $2 B$, lanes $N, P$, and $M$. This band could represent a "copy-back" defective genome, containing only the $\mathrm{N}, \mathrm{P}$, and $\mathrm{M}$ genes, that migrates slowly because of an extensive double helical structure. The amount of the M-F bicistronic transcript is increased (figure 2B, lanes $\mathrm{M}$ and F). This increment is accom- 

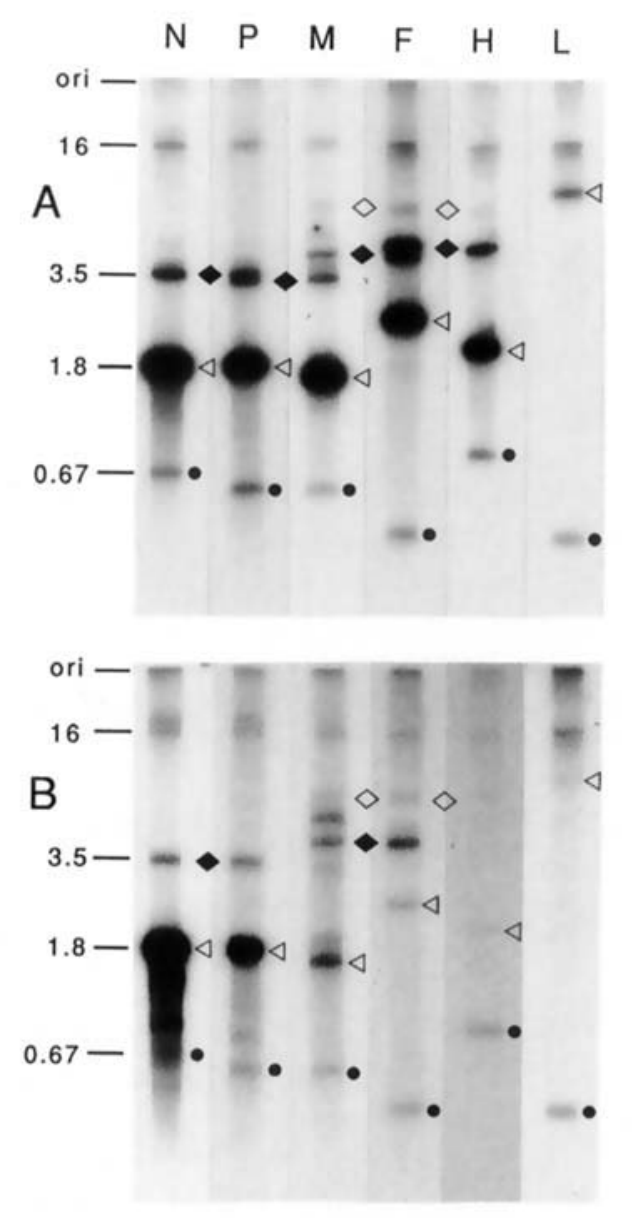

Figure 2. Northern blot analysis of six MV-specific transcripts: $(A)$ with total RNA derived from lytically infected HeLa cells and $(B)$ with total RNA derived from brain tissue from a patient with MIBE. In both cases $10 \mu \mathrm{g}$ of total RNA was loaded onto a broad slot of a $1.2 \%$ agaroseformaldehyde gel together with a mixture of standard RNAs [16] synthesized in vitro $(1.0 \mathrm{fmol}$ of each standard in $A$ and 0.1 fmol for $B$ ) and containing segments of MV mRNA species ( $\bullet$ ). After electrophoresis, the RNA was blotted onto nitrocellulose, which was cut into strips. Strips were then hybridized with different ${ }^{32}$ P-labeled RNA probes derived from the same plasmids as the unlabeled standards [16]. The monocistronic mRNAs $(\triangleleft)$, the bicistronic RNAs $(\diamond)$, and the tricistronic RNAs $(\diamond)$ are indicated. The lengths of the $N$ internal standard $(0.67$ kilobases), the $\mathrm{N}$ mRNA (1.8 kilobases), the N-P bicistronic RNA (3.5 kilobases), and the genome (16 kilobases) are indicated to the left of lane $N$. Ori $=$ origin.

panied, as expected, by a reduction in the amount of P-M and M-F bicistronic transcripts (not detectable) and by enhancement of the M-F-H tricistronic transcript.

To quantitate the data presented in figure $2 \mathrm{~B}$, we
Table 2. Copy numbers of MV transcripts per $10 \mathrm{pg}$ of total RNA.

\begin{tabular}{lcc}
\hline Transcript & HeLa cells & $\begin{array}{c}\text { MIBE } \\
\text { brain tissue }\end{array}$ \\
\hline $\mathrm{N}$ & 30000 & 4500 \\
$\mathrm{P}$ & 9000 & 1400 \\
$\mathrm{M}$ & 9500 & 180 \\
$\mathrm{~F}$ & 5500 & 60 \\
$\mathrm{H}$ & 4000 & 30 \\
$\mathrm{~L}$ & 500 & $\leqslant 15$ \\
M-F & 600 & 150 \\
$\quad$ Standard & 600 & 60 \\
\hline
\end{tabular}

NOTE. After exposure of the northern blots, bands corresponding to the $\mathrm{MV}$ transcripts and to the internal standards were cut out, and the amount of radioactivity bound was determined. The quantities of MV transcripts were related to $10 \mathrm{pg}$ of total RNA, which is the RNA content of an average cultured HeLa cell [16].

determined the amount of radioactivity of the different mRNAs in relation to the internal standard included in the assay (see the lower bands, marked with a dot, in each track of figure 2). The number of MVspecific transcripts, in brain tissue, involving mainly $\mathrm{M}, \mathrm{F}$, and $\mathrm{H}$ genes drops drastically in comparison with lytically infected HeLa cells (table 2). The amount of M-F bicistronic RNA is relatively high, equaling that of $\mathrm{M}$ mRNA and exceeding that of F mRNA.

In vitro translation reactions of isolated brain $m R N A s$. To test the biologic activity of the MV mRNAs present in the brain and to determine their ability to direct the synthesis of the corresponding proteins, we used an in vitro translation procedure to detect such synthesis. Only $\mathrm{N}$ and $\mathrm{P}$ proteins are synthesized, whereas $M$ protein is not made, despite the presence of its mRNA (figure 3). In addition, no $\mathrm{H}$ protein is synthesized in the in vitro translation reaction; this lack of synthesis may result from the low concentration of mRNA, as observed in the northern blot. It is not possible to make any statement about the $F$ protein because we could not detect it in control in vitro translation experiments using mRNAs from lytically infected cells [6].

\section{Discussion}

Our immunohistochemical and biochemical results indicate that $\mathrm{MV}$ persistence in brain cells from an individual with MIBE is characterized by the restriction of expression of three viral genes. In infected brain cells, only the $\mathrm{N}$ and $\mathrm{P}$ proteins of $\mathrm{MV}$ are con- 


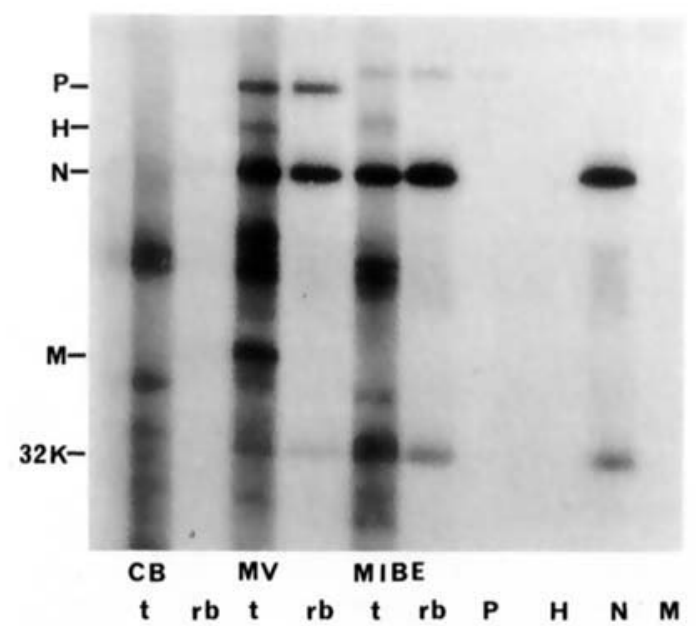

Figure 3. In vitro translation of mRNAs derived from control brain $(C B)$, lytic MV $(M V)$, or brain tissue from a patient with MIBE (MIBE). The products synthesized were either analyzed directly $(t)$ or after immunoprecipitation in $10 \%$ SDS-PAGE. $r b$, Immunoprecipitation with rabbit hyperimmune antiserum to $\mathrm{MV} ; P, H, N$, and $M$, immunoprecipitations with specific antisera.

sistently detected, and only the mRNAs of these two proteins are biologically active in an in vitro translation system. The expression of the $\mathrm{H}$ protein is reduced, whereas $\mathrm{M}$ and $\mathrm{F}$ proteins were not detectable in brain cells, despite the presence of their corresponding mRNAs. In part, this situation could be the result of the low concentrations of the mRNAs, particularly those for $\mathrm{F}$ and $\mathrm{H}$ proteins, which are significantly reduced when compared with values in lytically infected cells. However, because $M$ protein is not formed either in vivo or in vitro, although M mRNA is present in greater amounts than $\mathrm{H}$ mRNA, it seems likely that M mRNA is nonfunctional. A relatively large amount of M-F bicistronic RNA is found, an observation suggesting that the polymerase often does not recognize correctly the processing signal at the $\mathrm{M}-\mathrm{F}$ intercistronic region.

These findings are similar to previous observations made in SSPE. In this slow virus disease the synthesis of MV structural proteins in infected brain cells is also highly variable. As in MIBE, N and P proteins are consistently detected in each area of brain examined from individuals with SSPE, whereas $\mathrm{H}$, $\mathrm{F}$, and $\mathrm{M}$ proteins were either reduced in amount or absent $[8,12]$. The results of the biochemical analysis of MV gene expression in brains showing SSPE are rather complex $[5-7,15]$. Generally the mRNAs coding for MV N, P, and M proteins are easily detectable in brain tissues, whereas those for $\mathrm{H}$ and F proteins are strongly reduced in amount when compared with values in lytically infected cells. Although the amounts of viral mRNA within different parts of the same brain varied, the ratio of individual mRNAs remained constant. However, only the mRNAs for the $\mathrm{N}$ protein consistently directed synthesis of this polypeptide in in vitro translation systems, whereas $\mathbf{P}$ protein synthesis was detected in $75 \%$ of the subjects studied, and electrophoretic mobility shifts were encountered. Attempts to detect $\mathbf{H}$ protein in in vitro translations by using mRNA isolated from infected brain tissue were unsuccessful, either as a result of the relatively low concentration of this mRNA or of functional defects of the transcript. Of particular interest are the results obtained for $M$ protein. Despite the presence of intermediate levels of M mRNA in infected brain tissue in most of the cases studied, no in vitro product of this mRNA could be detected [6]. This translation defect of the M mRNA was further analyzed in one case. The sequence analysis of the $M$ gene revealed several differences from the Edmonston strain $\mathrm{M}$ sequence [17]. In particular, one base substitution was observed that created a stop codon at position 12 of the M-gene reading frame, an observation explaining why the $M$ protein could not be synthesized [17].

The lack of synthesis of MV envelope proteins could explain the failure to observe budding particles of virus and to isolate infectious virus from brains of individuals with MIBE. There is apparently no need for production of infectious particles of virus to perpetuate the infectious process in MIBE as in SSPE, because the MV nucleocapsid alone is infectious. In tissue culture experiments, isolated $\mathrm{N}$ structures - consisting of viral RNA and three viral structural proteins, $\mathrm{L}, \mathrm{P}$, and $\mathrm{N}$ - represent the replicative complex and are sufficient for maintaining viral replication in transfection experiments [18]. Therefore restriction of the expression of the MV envelope gene is not strictly deleterious to the survival of the persisting virus in brain tissue and may actually enable the virus to escape immune surveillance. For effective elmination of virus-infected cells, immune effector cells must recognize the viral structural proteins on the cell surface. In SSPE and MIBE, most infected brain cells do not demonstrate viral envelope proteins because these proteins are synthesized at very low levels if at all. Therefore infected brain cells can escape immune surveillance, and the 
replicative complex of MV can be spread in the CNS by means of cell-to-cell transport via cell processes.

Although our findings shed some light on the mechanisms of MV persistence in human brain tissue, they do not delineate which factors are involved in the establishment of persistence and how the observed replication defects develop. Antibody-induced antigenic modulation of $\mathrm{MV}$-infected cultured cells leads to persistence and affects viral replication [19]. Antibodies to MV remove viral glycoproteins from the surface of infected cells and reduce expression of some intracellular viral polypeptides. A marked perturbation of levels of the $P$ and $M$ proteins was observed when polyclonal antibody to $\mathrm{MV}$ was added to infected cultures. This mechanism may contribute to establishment of MV persistence in SSPE, where an immune defect has not been detected [20]. In MIBE, however, MV infection of brain tissue occurs in individuals with severe immunodeficiency, who are unable to respond properly to the infectious agent. In this disease, additional factors obviously interfere with MV replication in CNS tissue.

We observed recently that levels of the envelope proteins of MV are significantly reduced in infected brain cells of suckling Lewis rats at the onset of acute measles encephalitis [3]. This reduction in synthesis of $\mathrm{MV}$ proteins points to a rapid development of a defective multiplication cycle for the virus in rat brain in the absence of a measurable immune response. This observation suggests that factors independent of the immune system, probably specific for CNS cells, interfere with viral replication. Little is known about such factors, but in recent in vitro studies with papaverine, transcription of MV RNAs was inhibited, and a selective suppression of $\mathrm{M}$ protein synthesis occurred in neural cells [21, 22]. Many factors are clearly involved in controlling MV replication in brain tissue, and these factors determine whether an adventitious infection without further consequences ensues or a threat to the host with expression of altered viral genes and initiation of a pathological process is triggered.

\section{References}

1. Johnson RT. Chronic inflammatory and demyelinating diseases. In: Viral infections of the nervous system. New York: Raven Press, 1982:237-70

2. Ohuchi M, Ohuchi R, Mifune K, Ishihara T, Ogawa T. Characterization of the measles virus isolated from the brain of a patient with immunosuppressive measles encephalitis. J Infect Dis 1987;156:436-41
3. Liebert UG, ter Meulen V. Virological aspects of measles virus-induced encephalomyelitis in Lewis and BN rats. J Gen Virol 1987;68:1715-22

4. Morgan EM, Rapp F. Measles virus and its associated diseases. Bacteriological Reviews 1977;41:636-66

5. Baczko K, Carter MJ, Billeter M, ter Meulen V. Measles virus gene expression in subacute sclerosing panencephalitis. Virus Res 1984;1:585-95

6. Baczko K, Liebert UG, Billeter M, Cattaneo R, Budka H, ter Meulen V. Expression of defective measles virus genes in brain tissues of patients with subacute sclerosing panencephalitis. J Virol 1986;59:472-8

7. Haase AT, Gantz D, Eble B, Walker D, Stowring L, Ventura P, Blum H, Wietgrefe S, Zupancic M, Tourtellotte W, Gibbs CJ Jr, Norrby E, Rozenblatt S. Natural history of restricted synthesis and expression of measles virus genes in subacute sclerosing panencephalitis. Proc Natl Acad Sci USA 1985;82:3020-4

8. Liebert UG, Baczko K, Budka H, ter Meulen V. Restricted expression of measles virus proteins in brains from cases of subacute sclerosing panencephalitis. J Gen Virol 1986; 67:2435-44

9. Roos RP, Graves MC, Wollmann RL, Chilcote RR, Nixon $\mathrm{J}$. Immunologic and virologic studies of measles inclusion body encephalitis in an immunosuppressed host: the relationship to subacute sclerosing panencephalitis. Neurology 1981;31:1263-70

10. Carter MJ, Willcocks MM, Löffler S, ter Meulen V. Relationships between monoclonal antibody-binding sites on the measles virus haemagglutinin. J Gen Virol 1982; 63:113-20

11. ter Meulen V, Löffler S, Carter MJ, Stephenson JR. Antigenic characterization of measles and SSPE virus haemagglutinin by monoclonal antibodies. J Gen Virol 1981; 57:357-64

12. Norrby E, Kristensson K, Brzosko WJ, Kapsenberg JG. Measles virus matrix protein detected by immune fluorescence with monoclonal antibodies in the brain of patients with subacute sclerosing panencephalitis. J Virol 1985;56:337-40

13. Sheshberadaran H, Chen S-N, Norrby E. Monoclonal antibodies against five structural components of measles virus. I. Characterization of antigenic determinants on nine strains of measles virus. Virology 1983;128:3451-53

14. Sato TA, Fukuda A, Sugiura A. Characterization of major structural proteins of measles virus with monoclonal antibodies. J Gen Virol 1985;66:1397-409

15. Cattaneo R, Rebmann G, Baczko K, ter Meulen V, Billeter MA. Altered ratios of measles virus transcripts in diseased human brains. Virology 1987;160:523-6

16. Cattaneo R, Rebmann G, Schmid A, Baczko K, ter Meulen $\mathrm{V}$, Billeter MA. Altered transcription of a defective measles virus genome derived from a diseased human brain. EMBO J 1987;6:681-8

17. Cattaneo R, Schmid A, Rebmann G, Baczko K, ter Meulen V, Bellini WJ, Rozenblatt S, Billeter MA. Accumulated measles virus mutations in a case of subacute sclerosing panencephalitis: interrupted matrix protein reading frame and transcription alteration. Virology 1986;154:97-107

18. Rozenblatt S, Koch T, Pinhasi O, Bratosin S. Infective substructures of measles virus from acutely and persistently infected cells. J Virol 1979;32:329-33 
19. Fujinami RS, Oldstone MBA. Antibody initiates virus persistence: immune modulation and measles virus infection. In: Notkins AL, Oldstone MBA, eds. Concepts in viral pathogenesis. New York: Springer-Verlag, 1984:187-93

20. ter Meulen V, Stephenson JR, Kreth HW. Subacute sclerosing panencephalitis. In: Fraenkel-Conrat $H$, Wagner RR, eds. Comprehensive virology. Vol. 18. Virus-host interactions. Receptors, persistence, and neurological diseases. New York: Plenum Press, 1983:105-59
21. Miller CA, Carrigan DR. Reversible repression and activation of measles virus infection in neural cells. Proc Natl Acad Sci USA 1982;79:1629-33

22. Yoshikawa Y, Yamanouchi K. Effect of papaverine treatment on replication of measles virus in human neural and nonneural cells. J Virol 1984;50:489-96 